Article

\title{
Assessing the Role of Carbon Capture and Storage in Mitigation Pathways of Developing Economies
}

\author{
Panagiotis Fragkos (D)
}

check for updates

Citation: Fragkos, P. Assessing the Role of Carbon Capture and Storage in Mitigation Pathways of Developing Economies. Energies 2021, 14, 1879. https://doi.org/10.3390/ en14071879

Academic Editor: Muhammad Aziz

Received: 9 February 2021

Accepted: 24 March 2021

Published: 29 March 2021

Publisher's Note: MDPI stays neutral with regard to jurisdictional claims in published maps and institutional affiliations.

Copyright: (C) 2021 by the author. Licensee MDPI, Basel, Switzerland. This article is an open access article distributed under the terms and conditions of the Creative Commons Attribution (CC BY) license (https:/ / creativecommons.org/licenses/by/ $4.0 /)$.
E3Modelling S.A., Panormou 70-72, PO 11523 Athens, Greece; fragkos@e3modelling.com

\begin{abstract}
The Paris Agreement has set out ambitious climate goals aiming to keep global warming well-below $2{ }^{\circ} \mathrm{C}$ by 2100 . This requires a large-scale transformation of the global energy system based on the uptake of several technological options to reduce drastically emissions, including expansion of renewable energy, energy efficiency improvements, and fuel switch towards low-carbon energy carriers. The current study explores the role of Carbon Capture and Storage (CCS) as a mitigation option, which provides a dispatchable source for carbon-free production of electricity and can also be used to decarbonise industrial processes. In the last decade, limited technology progress and slow deployment of CCS technologies worldwide have increased the concerns about the feasibility and potential for massive scale-up of CCS required for deep decarbonisation. The current study uses the state-of-the-art PROMETHEUS global energy demand and supply system model to examine the role and impacts of CCS deployment in a global decarbonisation context. By developing contrasted decarbonisation scenarios, the analysis illustrates that CCS deployment might bring about various economic and climate benefits for developing economies, in the form of reduced emissions, lower mitigation costs, ensuring the cost efficient integration of renewables, limiting stranded fossil fuel assets, and alleviating the negative distributional impacts of cost-optimal policies for developing economies.
\end{abstract}

Keywords: energy system decarbonisation; PROMETHEUS model; Carbon Capture and Storage

\section{Introduction}

Following the ratification of the Paris Agreement by most countries globally, there is increasing consensus on the need to decarbonise global and regional energy systems in the next decades to ensure that global warming will not exceed $2^{\circ} \mathrm{C}$ or $1.5{ }^{\circ} \mathrm{C}$ by the end of century [1]. In this context, an increasing number of countries worldwide design ambitious long-term low-emission strategies while ensuring consistency with Sustainable Development Goals. In 2019, the European Union (EU) adopted the EU Green Deal aiming to become the first climate neutral continent by mid-century [2], while recently other major economies (China, Japan) made similar carbon neutrality pledges [3]. The structural transition towards carbon neutrality would be largely based on energy system decarbonisation, which requires the massive deployment of various technologies and strategies to reduce emissions from energy demand and supply sectors, combined with economic reorganization, new business models, labour re-skilling, low-carbon innovation, and disruptions in global value chains [4].

Recent literature acknowledges that large-scale emission reductions can be achieved with the expansion of renewable energy, mostly solar PV and wind driven by technology cost reductions, combined with phase-out of coal and oil-fired power plants, energy efficiency in demand sectors and electrification of energy services [5,6]. In this context, most studies confirm that Carbon Capture and Storage (CCS) technologies are also required in scenarios achieving the ambitious Paris Agreement goals, in order to abate remaining emissions from the power generation and industrial sectors [7,8]. Recent studies also examine the feasibility of $100 \%$ renewable energy systems at national and global level 
without the need for CCS deployment $[9,10]$. In the last decade, Carbon Capture and Storage has raised several concerns related to technology availability, high costs, public acceptability, and limited potential for storage of $\mathrm{CO}_{2}$ [11]. Recent studies suggest that CCS is technologically ready, but remains in the demonstration stage and will always cost more than comparable processes in which $\mathrm{CO}_{2}$ is not captured and stored, necessitating strong policy support, e.g., carbon prices [12]. The higher than expected challenges faced by CCS technologies in last decade have raised concerns about the potential for their massive upscale in the decarbonisation context. However, most model-based scenarios show that the deployment of CCS technologies is required to achieve ambitious transformation towards carbon neutrality in a cost-effective manner by 2050 [7,13], especially in countries where other emission reduction options face limitations, either due to political reasons (e.g., nuclear phase-out policies) or due to limited renewable potential because of climatic conditions (e.g., limited solar irradiation, low wind speeds). To drive the high expansion of CCS as required in future decarbonisation pathways, targeted policy support is required along with increased investment in Research and Development (R\&D) to bring down the costs and improve the performance of currently immature CCS options [14].

The objective of the study is to provide novel evidence on the potential role of CCS technologies in the context of global decarbonisation and develop a typology of potential benefits that CCS can provide for the required systemic transformation. The paper offers new insights on the challenges and opportunities for CCS uptake by 2050 focusing on developing regions and provides an improved understanding on the potential benefits that CCS may offer, in terms of reduced mitigation costs, lower risks for carbon lock-in and stranded assets, and alleviating the distributional impacts of climate policies. The study goes beyond existing literature by: (1) explicitly considering the interplay between CCS and other mitigation options towards climate neutrality in major emitters, (2) using an advanced version of the PROMETHEUS energy model, which fully incorporates the socio-economic impacts of COVID-19 pandemic, (3) exploring the impacts of most recent climate policy announcements of EU and China towards carbon neutrality, ensuring high policy relevance, and (4) analysing potential economic and environmental benefits of CCS expansion in developing economies.

The study proceeds as follows. Section 2 presents the current policy and technology landscape related to CCS technologies, while Section 3 includes the study design and methodological approach. Section 4 presents the results of the model-based assessment. Section 5 concludes.

\section{Policy and Technology Landscape Related to Carbon Capture}

2.1. The Current State of CCS Technologies Globally

Carbon Capture and Storage technologies can be used in most large emission sources (fossil-fired power plants and $\mathrm{CO}_{2}$ - intensive industry) and can capture more than $90-95 \%$ of the $\mathrm{CO}_{2}$ they produce, but they have experienced limited deployment over the last decade. Thus, CCS remains largely in the research and demonstration phase, without a large impact on global emissions and limited prospects for large-scale deployment in the medium term [15]. According to [16], only 40 million metric tons of $\mathrm{CO}_{2}$ from plants currently in operation are captured and stored each year, with only 51 large-scale CCS facilities in operation or under construction (most are located in the United States), while plants under development can provide additional capacity of around $60 \mathrm{MtCO}_{2}$ /year.

Carbon Capture and Use (CCU) applications face particularly high challenges related to the complexity and uncertainty about their emission reduction potential [15]. CCU technologies remain at the laboratory, prototype, and pilot phases and need targeted policy support towards their market uptake. $\mathrm{CCU}$ involves using $\mathrm{CO}_{2}$ as a feedstock to synthesise products of economic value, with the highest potential in sectors that deliver energy products, e.g., methanol, microalgae and methane, but require large amounts of energy consumption [17]. When carbon-rich fuel end-products are combusted, significant proportions of $\mathrm{CO}_{2}$ get emitted back into the atmosphere and several $\mathrm{CO}_{2}$ utilization 
avenues might be limited by energy availability. The above imply that the global $\mathrm{CO}_{2}$ utilization potential is limited to $1-2 \mathrm{Gt}-\mathrm{CO}_{2}$ per year currently [18] and might increase to $5 \mathrm{Gt}-\mathrm{CO}_{2}$ by 2050 , while the global geologic storage potential is about $10,000 \mathrm{Gt}-\mathrm{CO}_{2}$, existing mostly in saline aquifers; this is the reason why the current study focuses mostly on CCS applications, with CCU considered economically viable only for specific uses (e.g., in industrial applications) and countries. Several technologies can be used to capture $\mathrm{CO}_{2}$, including: post-combustion carbon capture (which is used in existing power plants), precombustion carbon capture (largely used in industrial processes), and oxy-fuel combustion systems. In post-combustion, $\mathrm{CO}_{2}$ is separated from the exhaust of a combustion process, while pre-combustion technologies are currently commercially available only for industrial facilities. This technology may be less costly than other CCS options, but it should be built into new facilities, as the costs to retrofit existing facilities with pre-combustion would be high. In oxy-fuel combustion, the fuel is burned in a nearly pure-oxygen environment, rather than regular air, which results in a more concentrated stream of $\mathrm{CO}_{2}$ emissions, which is easier to capture.

Once the $\mathrm{CO}_{2}$ is captured, it is compressed and transported to a storage site, usually by pipelines, ships or trains. Lastly, the $\mathrm{CO}_{2}$ is injected into underground geological formations, where it is stored, rather than being released into the atmosphere. Storage sites used for $\mathrm{CO}_{2}$ include former oil and gas reservoirs, deep saline formations, and coal beds. It should be noted that CCS increases cooling water usage in coal-fired power plants by up to $50 \%$ [19], which poses additional challenges to its uptake.

CCS technologies face significant barriers to large-scale deployment, related to their high costs, storage and transportation challenges, and uncertain public support. Although cost estimates vary widely, the greatest costs are typically associated with the equipment and energy needed for the capture and compression phases [20,21]. Capturing the $\mathrm{CO}_{2}$ can decrease plants' efficiency and increase their water use [19], and the additional costs posed by these and other factors can ultimately render a CCS project financially nonviable. Since CCS deployment is in its early stages, financial returns on a CCS project are riskier and investors impose higher risk premiums. The availability of geologic storage is considered a barrier to the widespread CCS deployment only in specific countries, as in most regions there is plenty of storage available. The transportation of $\mathrm{CO}_{2}$ is also costly as large amounts of energy are required to compress $\mathrm{CO}_{2}$ and maintain high pressure throughout $\mathrm{CO}_{2}$ transport pipelines [21], which are also expensive. Each source of $\mathrm{CO}_{2}$ (e.g., power plant) should be connected to an appropriate storage site, which increases costs to implement CCS projects in areas without appropriate geological formations. Finally, public support may also hamper the large-scale deployment of CCS, as its public acceptability is challenged by the low acceptance of pipelines construction, the perceived safety of transportation and storage of $\mathrm{CO}_{2}$, the potential uptake of other climate solutions and several other considerations [22].

In order to achieve carbon neutrality by mid-century, ambitious emission reduction options should be combined with removal of $\mathrm{CO}_{2}$ from the atmosphere that can be achieved by enhancing the natural carbon sink, by using engineering technologies or through a combination. The natural sink can be enhanced through ecosystems restoration, afforestation, reforestation, improved forest management and enhancing soil carbon sequestration. Other carbon dioxide removal (CDR) options include the use of biomass coupled with carbon capture and storage technologies (BECCS), direct air $\mathrm{CO}_{2}$ capture and underground storage, biochar, enhanced weathering, ocean alkalinisation, and ocean fertilization [15]. There is large uncertainty on the cost estimates of various CDR options provided by the literature, as related technologies are only at an exploratory stage and are not sufficiently mature for large deployment. Based on a recent comprehensive review [15], the costs of most CDR options can exceed $350 \$ /$ tn $\mathrm{CO}_{2}$, which, combined with their limited potential, imply high challenges for their market uptake at the global level [1]; these options can be used in countries where $\mathrm{CO}_{2}$ underground storage is not possible or not preferable The 
costs of afforestation, reforestation and soil carbon sequestration are relatively lower, but these options are not further considered, as the study focuses on energy system transition.

\subsection{Policies Related to CCS and Energy System Decarbonisation}

As CCS technologies cost more than fossil-fired plants without $\mathrm{CO}_{2}$ capture, their deployment requires strong policy support. This can take the form of carbon prices, which may reduce the competitiveness of fossil fuel power plants and incentivise increased investment in CCS technologies. The implementation of an ambitious and predictable policy and regulatory framework may mitigate the risks for investors, which is vital for incentivising investment, development, and uptake of CCS technologies. In order to realise the full-scale potential for cost and performance improvements, additional research and innovation is required to optimise technology design and integration. As highlighted in Intergovernmental Panel on Climate Change (IPCC) Special Report [13], the acceleration of CCS development requires policies that increase the demand for CCS as a low-carbon solution and reduce its costs. Different types of policies may bring down the costs of CCS and encourage research, development, and deployment, including carbon pricing, public investment, subsidies for low-carbon innovation, and clean energy standards that credit companies generating electricity with CCS.

The United States actively support the uptake of CCS, as demonstrated both by the amount of currently implemented CCS projects and by the multiple enacted policies that support and encourage the use of CCS technology. National tax credits for carbon sequestration are created through Section 45Q of the Internal Revenue Code, while several tax credits and other crediting mechanisms exist at the state level in California, Texas, Louisiana, Montana, and North Dakota. In addition to existing policy instruments, new policies are proposed to incentivise CCS development and deployment, including the Fossil Energy Research and Development Act of 2019, the Enhancing Energy Carbon Technology Act, and the Energy Advancement and Development through Innovations Act. Following the recent change in administration, the U.S. will re-enter the Paris Agreement, while accelerated climate action is expected focusing on renewable energy expansion, along with continued support for CCS technologies [23].

In the EU, the implementation of ambitious climate policies, in particular in the form of carbon pricing and Emission Trading System, would incentivise the uptake of CCS. However, the adoption of policies supporting renewable energy combined with rapidly decreasing costs of solar PV and wind, and public concerns for geological storage of $\mathrm{CO}_{2}$ have resulted in very limited progress on CCS uptake in most Member States. Recently, policies and regulations have been enacted to support deployment of CCS technologies, which can be considered in the Project of Common Interest (PCI) list to receive funding and accelerated implementation [24]. Moreover, research, demonstration and commercial CCS projects will also be eligible to receive EU funding under the Next Generation EU, the Innovation Fund and other similar instruments. In addition, the recent EU Taxonomy regulation [25] will apply a threshold of $100 \mathrm{~g} \mathrm{CO}_{2} \mathrm{e} / \mathrm{kWh}$ to electricity generation activities, which will make it impossible to invest in new fossil fired power plants without using the CCS technology or a high blend of low-emitting fuels. Lastly, the Commission intends to revise the Trans-European Networks for Energy(TEN-E) Regulation, including the eligibility criteria to qualify as PCI, with the construction of $\mathrm{CO}_{2}$ grids highly likely to receive funding from the Connecting Europe Facility [24], thus reducing risks for investors.

Carbon capture can be used to remove emissions from fossil-fired power plants and energy-intensive industrial processes. China has adopted policies to limit emissions from coal-fired power plants and promote the demonstration of Carbon Capture Use and Storage (CCUS). China has established activities focused on CCS through directives and incentives issued by various levels of government, mostly focusing on supporting individual projects/facilities, which are not always well publicised. While CCUS would be required for the transition to carbon neutrality, high upfront costs restrict CCUS in China to a handful of profitable industrial applications, a problem compounded by the COVID-19 pandemic. 
The country issued guidelines on a prospective national strategy for CCUS development in 2013 and later included the technology in a flurry of industrial and environmental policies at both national and local levels. However, unlike its approach toward other low-carbon innovations, such as renewable energy, China has not enshrined CCUS use in law and, thus, the country's unambitious CCUS laws and regulations are a major impediment to the sector's progress despite increasing attention from the government over the last decade.

\subsection{The Role of CCS in Mitigation Pathways}

The decarbonisation of electricity systems is an important mitigation option, as confirmed by various studies $[13,26]$. Renewable-powered systems will be viable over the coming decades, but it will be challenging to supply the entire system only with weatherdependent renewable energy [13], as economic, operational and regulatory challenges increase with higher shares of variable generation [14,27]. Recent studies indicate that large shares of solar PV and wind power can be integrated in power grids through increased storage capacities, grid expansions and greater demand response [28], but in most model-based studies assessing mitigation pathways, the use of CCS technologies plays an important role in climate-constrained scenarios [29]. Decarbonisation of electricity production is mainly driven by the high uptake of renewable energy especially solar and wind [30,31] combined with the expansion of CCS technologies, fired with fossil fuels or biomass. Variable generation can produce almost the entire electricity amounts in specific local contexts [32], but several operational and technical issues remain unresolved, while high amounts of investment in storage, grids, and flexible plants (with low utilisation rates that cannot recover fixed costs) would be required $[13,29]$.

Consequently, most mitigation scenarios consider the deployment of CCS technologies in power generation and industrial processes in cost-optimal mitigation scenarios, both at the global $[14,15]$ and national/regional levels $[13,33]$, showing that CCS uptake is compatible with the Paris goals. As inclusion of CCS in the energy mix increases, the fossil energy use increases under decarbonisation policies, while the Gross Domestic Product (GDP) losses also reduce [8,34]. Most studies show that fossil fuel phase out may be delayed, as these are increasingly used in CCS applications and remain significant in the energy mix by 2050 [33,35], but the deployment of CCS is outpaced by massive retirements of fossil fuel fired power plants [36]. Several model-based analyses show that under stringent climate restrictions, CCS technologies will be used both with fossil fuels and with bioenergy [13].

Global coal consumption needs to be largely eliminated by 2040-2060 to limit warming to $2{ }^{\circ} \mathrm{C}[13,14]$, indicating that new coal infrastructure would likely be inconsistent with the Paris goals. Coal use is expected to decline already in the short-term in the EU and the U.S., as other energy sources become more economic, while the complete coal phase-out before 2050 in developing economies is more challenging given the low age of their power plant fleet [37]. In contrast, natural gas is projected to remain a significant part of the global energy system in most $2{ }^{\circ} \mathrm{C}$-compatible mitigation pathways, especially when combined with high deployment of CCS technologies [14].

Energy system restructuring may require large-scale premature retirements of carbonintensive power plants globally [27,33], with coal and gas-fired power plants retiring about 20 to 30 years earlier relative to historical rates [38]. Since the value of capital depreciates over the years, developing countries face higher stranded asset risks [29], especially in China and India with large fleet of newer fossil infrastructure. Recent literature shows that stranded assets can be reduced with early climate action [39] or with retrofitting fossil-fired power plants with CCS technologies [33].

\section{Methodology}

In order to consistently explore the challenges and potential benefits of CCS uptake in the low-carbon transition, the emission, energy, and economic impacts of ambitious climate scenarios are explored using the state-of-the-art PROMETHEUS energy system model, which has been extensively used for climate policy analysis [26,27]. 


\subsection{The PROMETHEUS Energy System Model}

PROMETHEUS is a fully-fledged world energy system model, which represents in detail the potential developments in the energy sector under alternative policy and technology scenarios until 2050 [40]. The model combines a top-down simulation of energy demand by sector, largely based on econometrically estimated equations, with a bottom-up representation of energy, electricity, and transport technologies and infrastructure. By including a complete accounting of energy demand and supply by sector and energy product, PROMETHEUS simulates the complex interactions between demand and supply to form market equilibrium at the regional and global energy markets with endogenous formulation of energy prices. PROMETHEUS includes specific modules for the macro-economy, energy demand by end-uses, electricity and hydrogen production, energy pricing, $\mathrm{CO}_{2}$ emissions from fossil fuels, hydrocarbon supply and technology learning. The modules are linked together to form a comprehensive global energy system model (Table 1) and interact with each other through their common variables and system constraints (e.g., on emissions or renewable energy targets).

Table 1. PROMETHEUS model regions.

\begin{tabular}{cc}
\hline Abbreviation & Country/Region \\
\hline EU + NO & The European Union Member States plus the UK and Norway \\
North America & The United States of America and Canada \\
ROECD & Japan, South Korea, Australia, and New Zealand \\
China & China and Hong Kong \\
India & India \\
CIS & The former Soviet Union excluding the Baltic Republics \\
MENA & The Middle East and North Africa region \\
RESTW & All other countries, mostly economies in Africa, Latin America, and Asia \\
\hline
\end{tabular}

In PROMETHEUS, energy demand arises from three main consumption sectors, i.e., transport, buildings and industries, while several subsectors are identified, including road transport, aviation, bunkers, electric appliances, space and water heating, cooking, steam, industrial processes etc. Explicit technologies are integrated to represent energy and mobility services, e.g., different types of private cars are represented including conventional Internal Combustion Engine (ICEs), hybrids, plug-in hybrids, and electric vehicles. Power generation requirements are determined by the electricity consumption in buildings, industries and transport, grid losses, the security of supply margin (and other flexibility constraints), and own consumption of power plants [26]. To represent real-world heterogeneities in investment decisions, new capacity is allocated to power generating technologies [1], depending on their total levelised cost, which includes capital, fixed and variable operation and maintenance costs, and fuel costs. The electricity system operation is simulated based on dispatching of power plants, determined by the load duration curve, their installed capacities, and operating costs. Low-carbon technology progress is endogenous through learning by doing and learning by research, with learning rates derived from [41]. Details on PROMETHEUS technologies can be found in [40]. The modelling combines economic foundations with the representation of agents' behaviour (e.g., energy consumers, power producers) as well as technical and engineering constraints of the electricity system. Energy demand, electricity supply, and energy efficiency are explicitly represented through technologies in each sector, including conventional and innovative low-emission options (i.e., renewable energy, buildings' renovation, electric vehicles, advanced biofuels, CCS, hydrogen).

PROMETHEUS can simulate the impacts of energy and climate policies on regional and global energy system developments, energy prices and $\mathrm{CO}_{2}$ emissions. Various climate policy instruments (e.g., carbon tax, cap-and-trade systems) and energy-related measures (e.g., targets on renewable energy or energy efficiency, subsidies to specific technologies, energy labelling etc.) are represented (Figure 1). The implementation of ambitious cli- 
mate policies would result in a large-scale energy system restructuring, driven by energy efficiency, renewable energy expansion and inter-fuel substitutions towards low-carbon energy carriers (e.g., electricity, biofuels). In case of stringent climate targets, the upscale of carbon dioxide removal, mostly in the form of biomass with carbon capture and storage (BECCS), may also be required [1]. The regional dynamics of energy demand and supply, fossil fuel exploitation potential, inter-fuel substitutions, and technology assumptions drive the projections for international fossil fuel prices, which are endogenously calculated in PROMETHEUS [26].

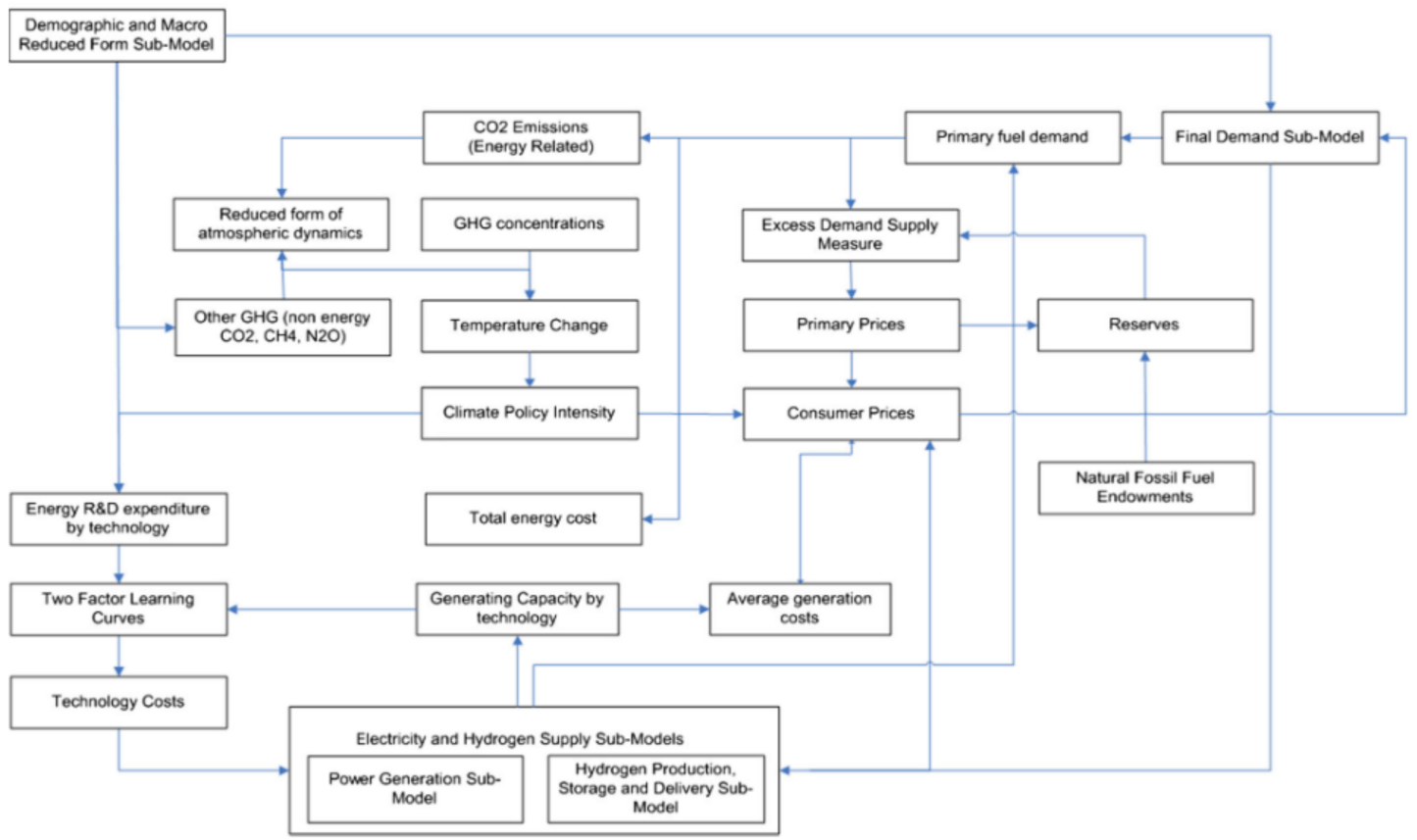

Figure 1. PROMETHEUS flow chart.

PROMETHEUS includes various Carbon Capture and Storage options based on postcombustion, pre-combustion and oxy-fuel processes combined with coal, gas, or biomassfired power plants. Driven by carbon pricing, CCS competes with other emission abatement options, such as renewable energy and nuclear power. The power plants equipped with CCS are more expensive in terms of capital and Operation and Maintenance (O\&M) costs and have lower net thermal efficiency compared to similar plants without carbon capture. Therefore, the deployment of CCS technologies crucially depends on the imposition of carbon pricing which improves the relative competitiveness of CCS vis-à-vis fossil fuel power plants [13]. To simulate the increasing difficulty to deploy suitable sites to store carbon dioxide, PROMETHEUS simulates non-linear cost-supply curves for underground $\mathrm{CO}_{2}$ storage, based on [42]. The model uses costs estimations for CCS technologies of [20] with $\mathrm{CO}_{2}$ capture costs higher than USD $50 / \mathrm{t}-\mathrm{CO}_{2}$ for most technologies, while the capital cost of a fossil-fired power plant with CCS is almost double than without CCS and the energy penalty of CCS further increases fuel costs. As CCS technologies face public acceptance issues in various countries, these can be simulated through model parameters lowering the CCS potential and making the technology more expensive. BECCS can also be used to produce electricity with net negative emissions, but their deployment highly depends on the stringency of climate policies, the development and market uptake of CCS and the supply of large amounts of biomass in a sustainable way, without negative environmental and land impacts. 


\subsection{Study and Scenario Design}

Alternative policy scenarios are modelled with PROMETHEUS to assess the energy system, cost, and emission implications of alternative climate policy and technology settings (Table 2).

Table 2. Scenario description.

\begin{tabular}{|c|c|c|}
\hline & Scenario Description & Global Climate Targets \\
\hline REF & Reference scenario & $\begin{array}{l}\text { Countries meet national policies, but policy } \\
\text { ambition does not increase after } 2020\end{array}$ \\
\hline 2DEG-OPT & $\begin{array}{c}\text { Decarbonisation to } 2^{\circ} \mathrm{C} \text { with all } \\
\text { options available }\end{array}$ & $\begin{array}{l}\text { All countries adopt universal carbon pricing } \\
\text { from } 2020 \text { onwards to meet the global carbon } \\
\text { budget of } 900 \text { Gt over } 2010-2050\end{array}$ \\
\hline NOCCS & Decarbonisation to $2{ }^{\circ} \mathrm{C}$ but without CCS uptake & Same as above \\
\hline Delayed & $\begin{array}{c}\text { Decarbonisation to } 2^{\circ} \mathrm{C} \text { with all } \\
\text { options available }\end{array}$ & $\begin{array}{c}\text { Delayed climate action starting from } 2030 \\
\text { onwards globally }\end{array}$ \\
\hline NOCCS_Delayed & Decarbonisation to $2{ }^{\circ} \mathrm{C}$ but without CCS uptake & Same as above \\
\hline
\end{tabular}

The reference scenario is a projection for the future development of the energy and economy system based on the continuation of historical and current trends and a range of assumptions on socioeconomic evolution, energy and climate policies, technology progress, and energy resources. It assumes that already legislated climate policies are implemented in all regions until 2020 following [1], but no new policies are introduced after 2020; this represents a lack of climate policy ambition, with the reference not being compatible with the Paris Agreement goals. The scenario assumes that carbon intensity of GDP after 2020 improves at rates comparable to the period before 2020. Carbon values and specific policy measures are introduced in Reference to ensure that emission and RES capacity targets of major emitters are implemented. The macro-economic (including population and GDP) and international energy price assumptions are based on [14] and are consistent with the Shared Socioeconomic Pathway (SSP)2 scenario [43]. The costs of power generation technologies follow the projections of [44], while technology progress is assumed for clean energy technologies [41], including wind onshore and offshore, solar PV, electric vehicles, batteries, CCS, and advanced biofuels.

The 2DEG-OPT scenario assumes that emission abatement measures are implemented globally, so as to limit cumulative global $\mathrm{CO}_{2}$ emissions to the level of $900 \mathrm{Gt}$ over 2010-2050 [5], which is used as a proxy for the well-below $2{ }^{\circ} \mathrm{C}$ target. After 2020, emission reduction occurs when and where it is cost-optimal, based on the implementation of a global carbon price, which increases from $63 \$ / \mathrm{tnCO}_{2}$ in 2030 to $305 \$ / \mathrm{tnCO}_{2}$ in 2050, indicating the high difficulty to reduce emissions in sectors, such as heavy industry and aviation. The global emission constraint is achieved in a cost-optimal way, driven by the equalization of marginal abatement costs across regions and sectors, without implementing burden-sharing schemes and equity principles. In the 2DEG-OPT scenario, all emission reduction options (including renewable energy, CCS, nuclear, energy efficiency, electrification, biofuels, hydrogen) are available and can be massively deployed based on their cost efficiency to achieve the emission constraint. The low-carbon transition is induced by ambitious policy signals, accelerated technology development through the endogenous learning mechanisms of PROMETHEUS, effective coordination of market players (industries, consumers), the removal of non-market barriers, and favourable conditions for investment in low-carbon technology, equipment and infrastructure. The 2DEG-OPT scenario includes stylised climate policies in the form of universal carbon pricing across regions and sectors, which may face implementation challenges related to difficulties in establishing a global carbon pricing regime, as currently most countries consider mostly domestic climate policies.

The role of alternative mitigation options is assessed through scenario analysis, focusing on possible limitations preventing the massive deployment of CCS technologies, 
driven by a range of social acceptance, technology and economic factors [11,22]. Given the limitations related to CCS uptake, the study investigates whether alternative mitigation strategies may reduce the need for CCS and what are the related implications, challenges and costs. In the absence of CCS development, other mitigation options (e.g., renewable energy) have to be deployed at higher levels relative to those in the 2DEG-OPT scenario, thus increasing total energy system costs to achieve the same climate target. This may require additional energy savings and further expansion of weather-dependent renewable energy combined with storage and grid expansion. In order to explore the decarbonisation impacts on premature retirements of fossil fuel power plants, two additional scenarios are quantified, which assume that ambitious climate action is delayed worldwide and starts only after 2030, thus posing additional challenges for achieving the long-term climate target and potentially increasing the risks for stranded fossil fuel assets as in [7].

\section{Scenario Results}

The section explores the energy system, technology and economic impacts of ambitious climate policies towards achieving the Paris Agreement goals.

\subsection{Impacts on $\mathrm{CO}_{2}$ Emissions}

The application of universal carbon price from 2020 onwards would result in a large decline of global $\mathrm{CO}_{2}$ emissions from fossil fuel combustion (Figure 2). Here, it should be noted that due to COVID-19 pandemic, global $\mathrm{CO}_{2}$ emissions have decreased by about 7\% in 2020 from 2019 levels [45]. The analysis shows that the 2DEG-OPT would lead to a constant decline of emissions, starting already in 2020 with the emission peak happening already in 2019, while in previous assessments, the peak was projected later, around 2025 [14]. This points to the need of formulating ambitious green policy measures in the context of socio-economic recovery from COVID impacts [46] aiming to contribute to sustainable development and avoid a rebound of emissions once global activity starts growing again. In the 2DEG-OPT scenario, the increasing carbon price drives an extensive reduction of global $\mathrm{CO}_{2}$ emissions, which are projected to decline by $19 \%$ in $2030,48 \%$ in 2040, and 76\% in 2050 relative to their 2020 levels. The electricity sector is the first to decarbonise with coal-fired based generation rapidly declining by 2035 , while emission reductions from demand sectors are mostly driven by energy efficiency improvements, electrification of energy services (e.g., through electric vehicles and heat pumps) and fuel switch towards low-carbon energy carriers, including biofuels and hydrogen. In 2050, global $\mathrm{CO}_{2}$ emissions amount to only $7.4 \mathrm{Gt}$, which is in line with IPCC Assessment [13] and mostly derive from hard-to-abate sectors, such as heavy industry, freight road transport, and bunkers. The electricity sector is fully decarbonised by 2045 based on large scale expansion of renewable energy and CCS technologies, while the emergence of BECCS after 2045 leads to net negative emissions from global electricity production in 2050. 


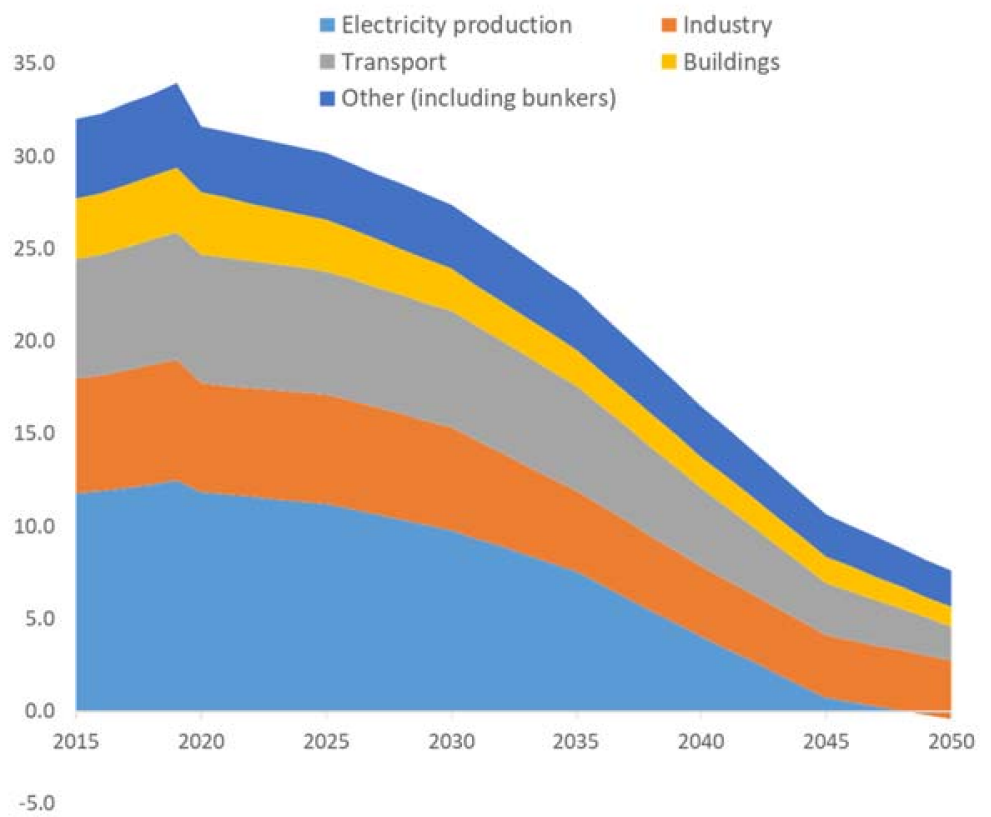

Figure 2. Global $\mathrm{CO}_{2}$ emissions by sector in 2DEG-OPT scenario in the period 2015-2050 (in $\mathrm{Gt}_{2} \mathrm{CO}_{2}$ ).

In case that CCS deployment faces severe economic, social acceptability, or technological barriers (NOCCS scenario), $\mathrm{CO}_{2}$ emissions are slightly higher in 2050, as the higher uptake of other mitigation options (e.g., renewable energy, nuclear power) is not sufficient to lead to the same emission reduction achieved in the 2DEG-OPT scenario. This effect is more relevant for the developing economies (Figure 3), where $\mathrm{CO}_{2}$ emissions in 2050 in the NOCCS scenario are about $9 \%$ higher than in 2DEG-OPT, given that electricity production cannot be fully decarbonised in the absence of CCS technologies, as flexible power generators are required (mostly in the form of combined cycle gas turbines) to provide flexibility and balancing to the system that is massively dominated by weather-dependent renewable energy sources (e.g., solar PV, wind). In addition, electricity prices are higher than in 2DEG-OPT as the power mix is not cost-optimal (in the absence of CCS), thus increasing the challenges to decarbonise other sectors that depend on massive electrification, such as buildings and transport.

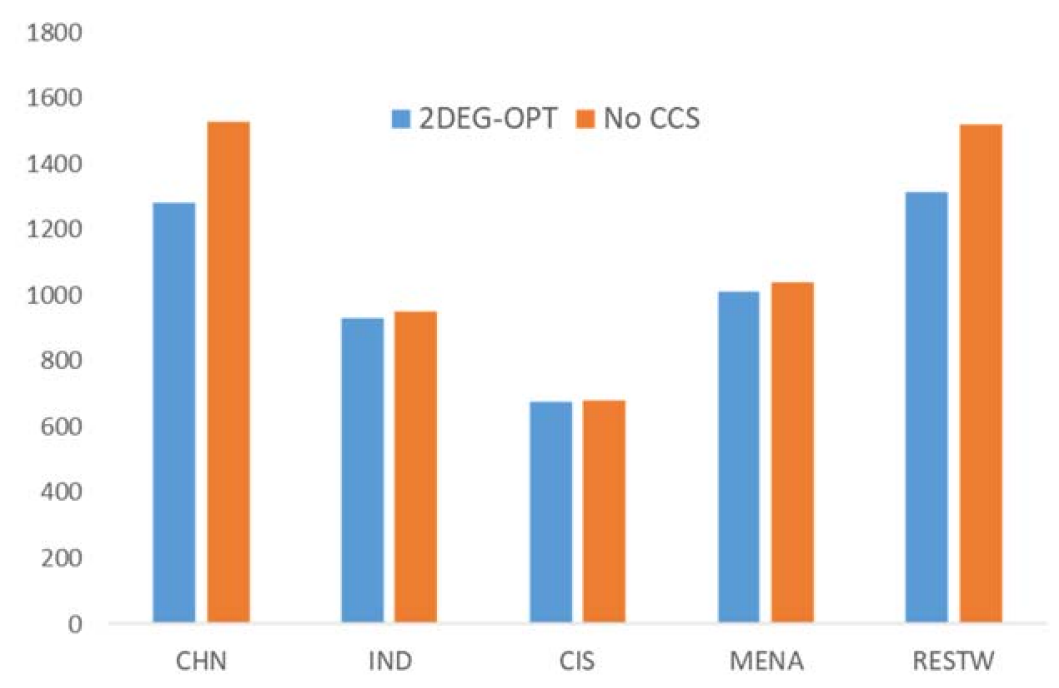

Figure 3. $\mathrm{CO}_{2}$ emissions of developing regions in 2050 (in $\mathrm{Mt} \mathrm{CO}_{2}$ ). 


\subsection{Impacts on Global Energy System Transformation}

In the context of high carbon pricing, the global energy system is set for a rapid transformation away from the current fossil-fuel based paradigm and towards a diversified energy supply system with large expansion of renewable energy (Figure 4) and increased use of nuclear power, while the remaining fossil fuels would be used either in combination with CCS technologies or in sectors with limited available mitigation options (e.g., bunkers, heavy industry).

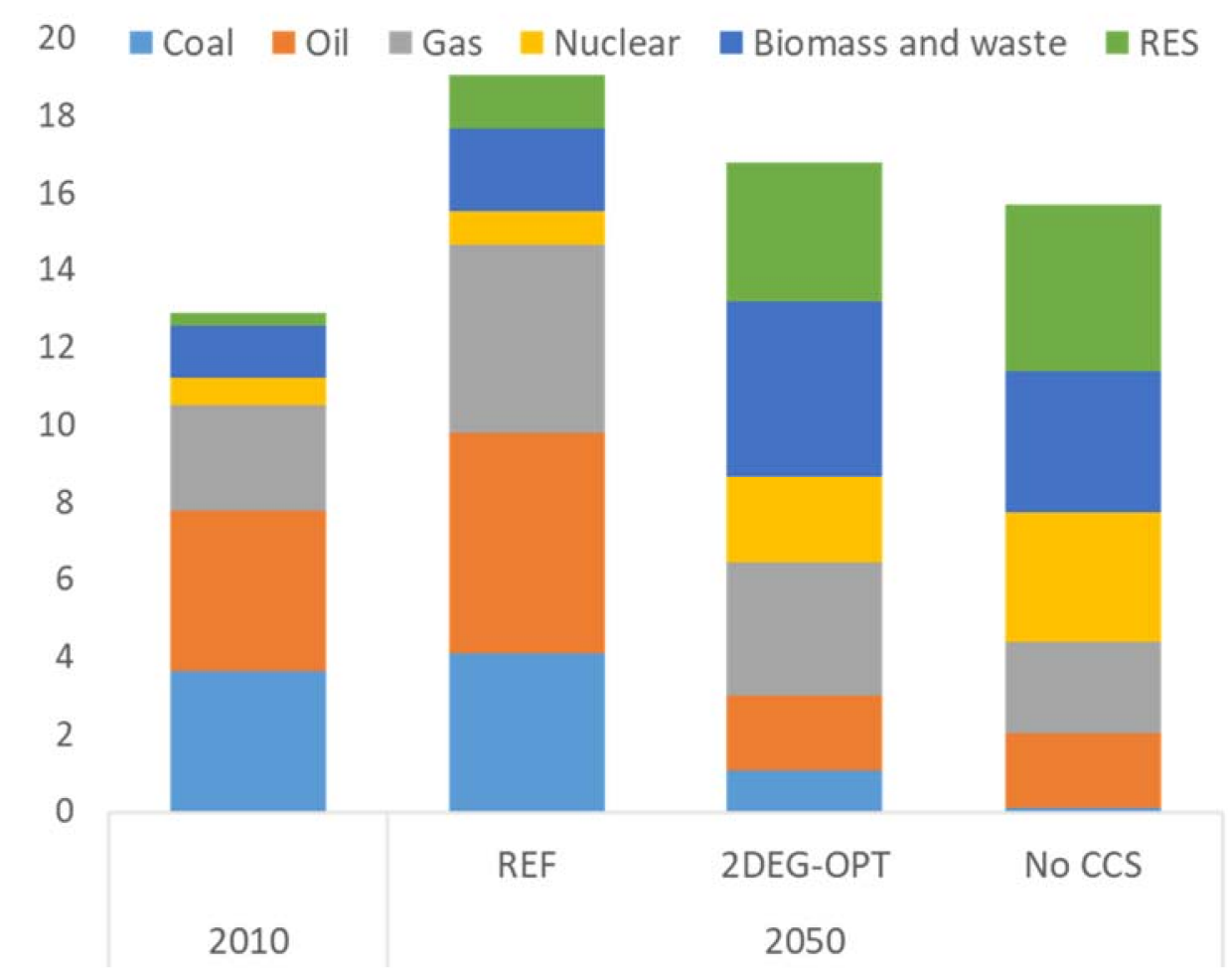

Figure 4. Global primary energy production by fuel in alternative scenarios (in Gtoe- Giga tonnes of oil equivalent).

In the absence of ambitious climate policies, the reference scenario shows a continuation of past trends with fossil fuels dominating the global energy supply, but with a slightly declining share (from $81 \%$ in 2015 to $74 \%$ in 2050), driven by technological improvements in renewable energy technologies, increased fossil fuel prices, and energy intensity improvements. The decarbonisation scenarios result in a drastic change of primary energy supply mix, with a rapid increase in the share of renewable energy, from 13\% in 2010 to $47-52 \%$ in 2DEG scenarios in 2050, largely driven by the rapid uptake of solar and wind power and advanced biofuels to reduce emissions from the electricity and transport sector respectively. In addition, energy requirements decline from Reference levels driven by energy efficiency measures in households, industries and transport, deep renovation of buildings and uptake of more efficient energy carries (e.g., electricity), equipment and technologies (Figure 4). These trends imply that global fossil fuel consumption would decline by $39-58 \%$ over $2010-2050$, in line with IPCC findings [13]. When comparing the two 2DEG scenarios, fossil fuel consumption is higher in 2DEG-OPT as CCS technologies are used to eliminate emissions from fossil fuel-fired power plants. In case that carbon capture is not available (NOCCS scenario) other mitigation options, including renewable energy, nuclear power and energy efficiency, are more aggressively deployed.

The model-based analysis confirms that the electricity sector is the first to decarbonise in the medium-term (in line with $[13,14]$ ), as several emission reduction options are already available and cost-competitive with fossil-fired power plants in most regions (e.g., solar PV, onshore and offshore wind, hydro). The share of coal is projected to decline by half over 
2015-2030, demonstrating that large emission reductions can be achieved with substitutions towards cleaner electricity producing technologies replacing carbon-intensive options (Figure 5). Renewable energy technologies are massively deployed globally, driven by their reduced costs combined with increased costs to use fossil fuels due to high carbon pricing. The share of RES in global power generation increases from $20 \%$ in 2010 to $48 \%$ in 2030 and further to $72-78 \%$ in 2050 (including hydro and biomass), while nuclear power also expands from $11 \%$ in 2015 to $13-18 \%$ in 2050 . The absence of CCS implies that, in order to achieve the same emission goal, the deployment of nuclear and renewable energy should be higher relative to the cost-optimal 2DEG-OPT scenario, requiring additional amounts of capital-intensive investment in nuclear power plants, wind farms, PV installations and hydro-electric plants. In all cases, global power production is almost fully decarbonised by 2050 with the share of unabated fossil fuel fired plants declining to only $3 \%$ in 2050, mostly through gas-fired power plants that provide flexibility and balancing services to accommodate the large amounts of variable renewable energy in the system. The deployment of carbon capture depends on specific scenario assumptions, with CCS technologies accounting for about $19 \%$ of global power requirements in the 2DEG-OPT scenario, as they can provide a dispatchable emission abatement option to balance weather-dependent electricity generation (Figure 6). CCS options are combined both with fossil fuels and with biomass in the form of BECCS leading to net negative emissions.

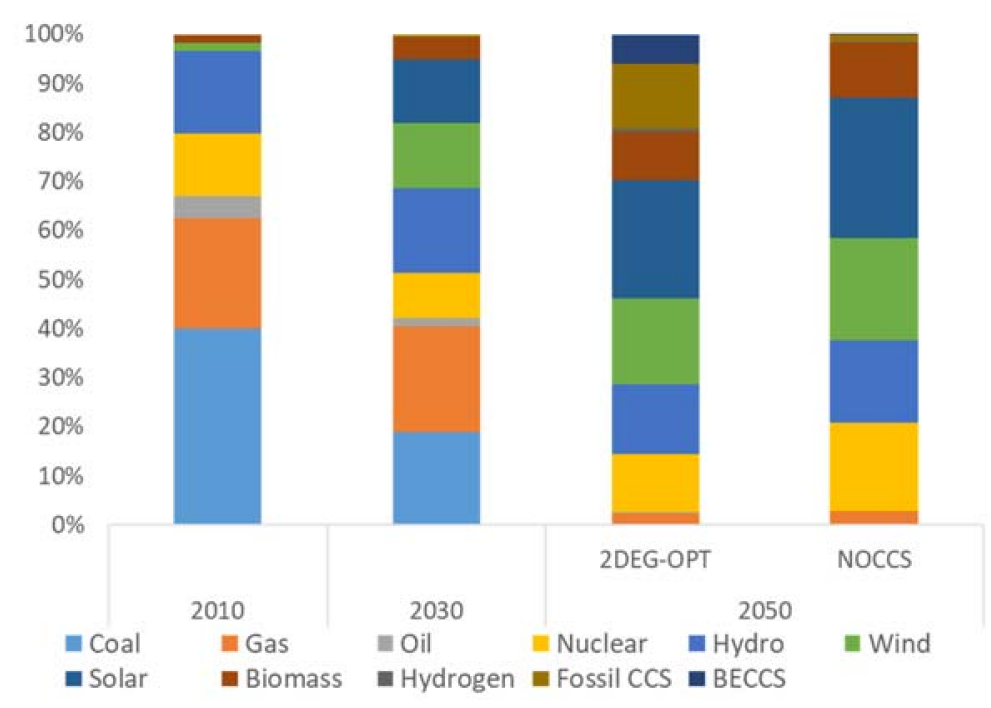

Figure 5. Global power generation mix by technology over 2010-2050 (in \%).

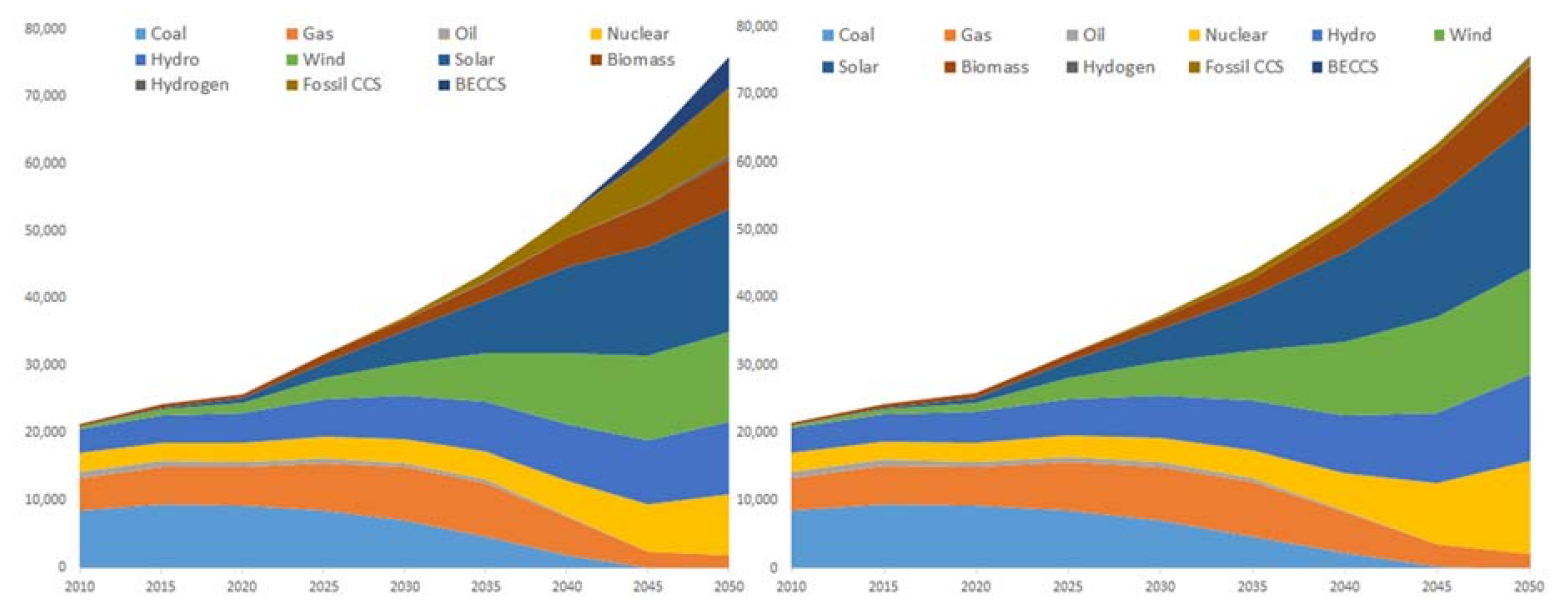

Figure 6. Global electricity production by technology over 2010-2050 (in TWh). 


\subsection{Impacts on Energy Systems of Developing Countries}

Section 4.3 presents the impacts of decarbonisation on the energy system of developing regions. Driven by ambitious climate policies and high carbon pricing, the energy sector of developing regions is set for a large-scale transformation driven by reduced consumption of fossil fuels over 2015-2050, which ranges from 23\% in 2DEG-OPT to 50\% in NOCCS scenario. The fossil fuel markets benefit from the emergence of CCS technologies, with the gas market of developing economies even increasing from 2015 levels. High carbon pricing mostly penalises the combustion of coal, which has the highest carbon intensity among fossil fuels, with coal consumption declining by 66-95\% over 2015-2050. Natural gas would remain a relevant fuel, especially in major hydrocarbon producers (such as Commonwealth of Independent States (CIS) and Middle East and Norther Africa (MENA), but also in China and India where gas may substitute coal in power generation and in industrial applications, due to its lower carbon intensity. The model-based findings suggest that wind, solar, bioenergy and nuclear power are increasingly deployed to satisfy the increasing energy requirements of developing countries as their incomes grow, while the expansion of hydro-electricity is constrained by its relatively limited untapped potential in most regions [7]. Overall, energy system decarbonisation is driven by the rapid uptake of renewable energy, energy savings, electrification of end uses and fuel switch towards low-emission energy carriers, such as biofuels (Figure 7).

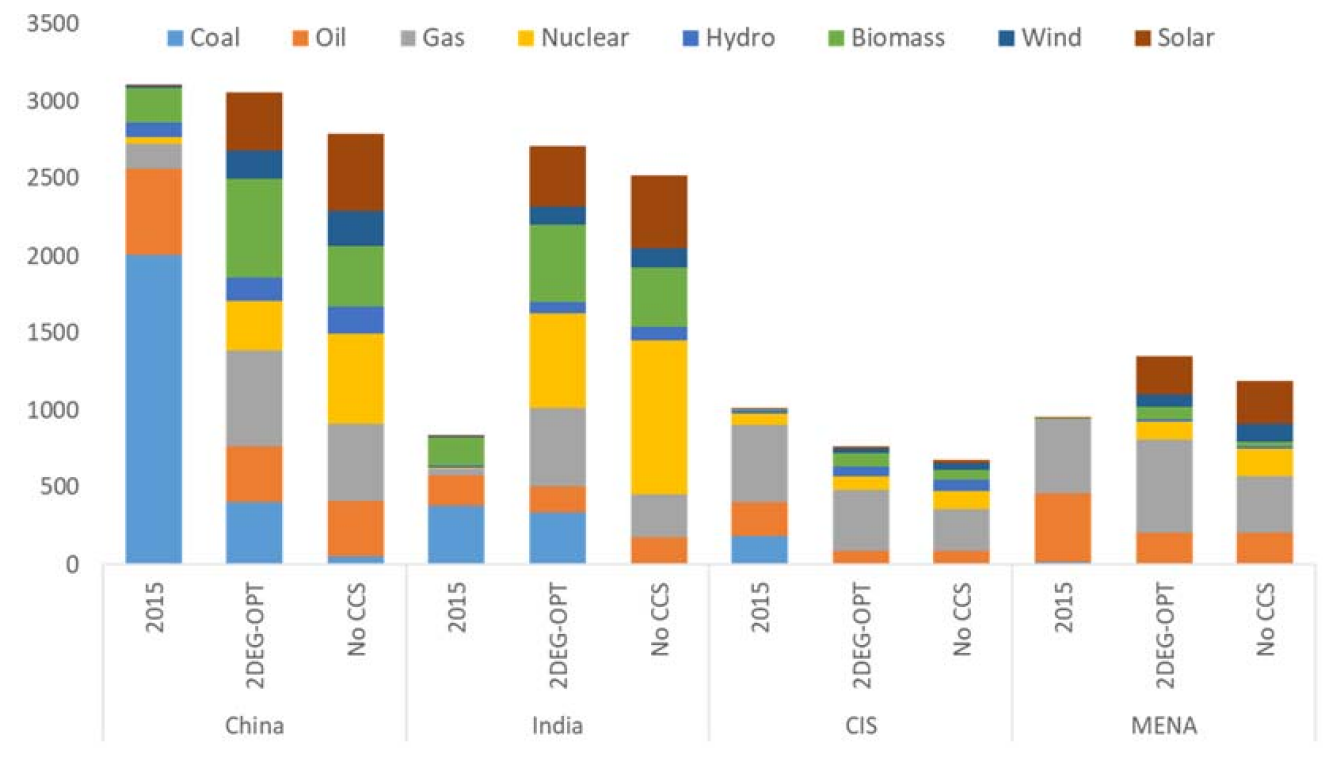

Figure 7. Primary energy consumption by fuel in developing economies in 2050 (in Mtoe).

As China is currently the largest emitting and energy consuming economy, its system transformation towards decarbonisation has large impacts for the global effort towards meeting the Paris Agreement goals. The Chinese power generation sector is currently dominated by coal and hydro, having a share of $70 \%$ and $19 \%$, respectively, in 2015 . Solar PV and wind technologies have emerged recently, induced by their cost reductions, domestic climate policies, and increasing concerns about air pollution caused by coal combustion; the latter has resulted in a relative stabilisation of Chinese coal production in recent years. This trend accelerates significantly in the 2DEG scenarios, where the joint share of solar and wind is projected to increase from 4\% in 2015 to $27 \%$ in 2030 and further to $44-57 \%$ in 2050 , with the highest share registered in the NOCCS scenario where the carbon capture option is not available. In both decarbonisation cases, unabated gas-fired power plants (i.e., without carbon capture) account for only $4-5 \%$ of electricity requirements in 2050 and are mostly used to balance the stochastic generation from intermittent sources. In the absence of CCS, the uptake of other low-emission options, including solar, wind, hydro, and nuclear power, increases even faster than in 2DEG-OPT scenario. The decarbonisation 
of China's power generation mix enables the accelerated electrification of energy end uses through the uptake of electric vehicles and heat pumps, allowing to reduce emissions from sectors with limited availability of mitigation options, such as transport, buildings, and industries (Figure 8).

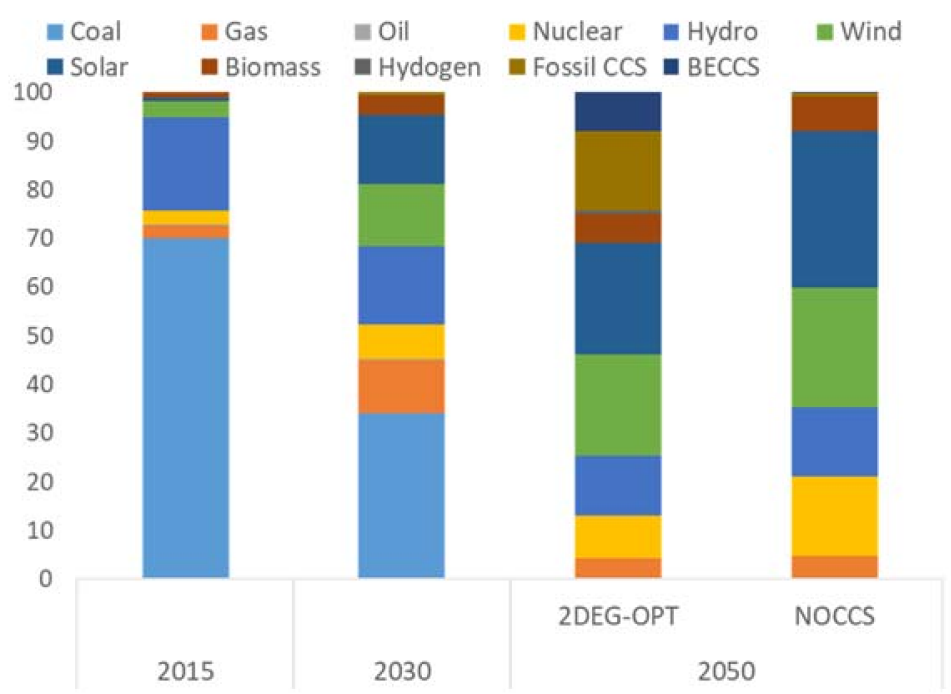

Figure 8. China's power generation mix by technology in alternative scenarios over 2015-2050.

\subsection{Impacts for Stranded Fossil Fuel Assets}

The coal sector is currently under pressure as it faces high competition from gas and renewable energy, with coal consumption declining in all developed economies, but recently also in low-income countries as a result of COVID-19 impacts. Recent developments in the coal market indicate that the number of cancelled plants is increasing, while new coal capacity additions face increasing difficulties worldwide [39]. Carbon pricing would force reduced operation of existing fossil-fired power plants and pose additional challenges to recover the plants' variable and fixed operational costs, leading to their premature retirement; these plants are considered to be stranded.

To meet the Paris Agreement goals, a complete phase-out of coal-based power plants without CCS is required by mid-century, while gas-fired capacities also significantly decline. However, continued investment in fossil-fired power plants in major economies poses additional challenges for the transition, as they increase the amount of stranded assets and fossil fuel capacity that has to be phased out before the end of its lifetime. The implications of various climate policy settings with regard to stranded assets in developing countries are shown in Figure 9. The amount of stranded assets is higher in case of delayed climate action (where decarbonisation effort starts after 2030) and in case that CCS technologies are not deployed. However, the emergence of carbon capture options and the early implementation of carbon pricing in the 2DEG-OPT scenario would significantly reduce the amount of stranded assets, as the investment in new fossil-fired power plants decline already in the decade 2020-2030. In developing economies, the 2DEG-OPT scenario leads to $450 \mathrm{GW}$ of stranded power assets across developing economies, which may increase by a factor of 3.2 and reach about $1400 \mathrm{GW}$ in case of delayed climate action and limitations in the uptake of CCS. 


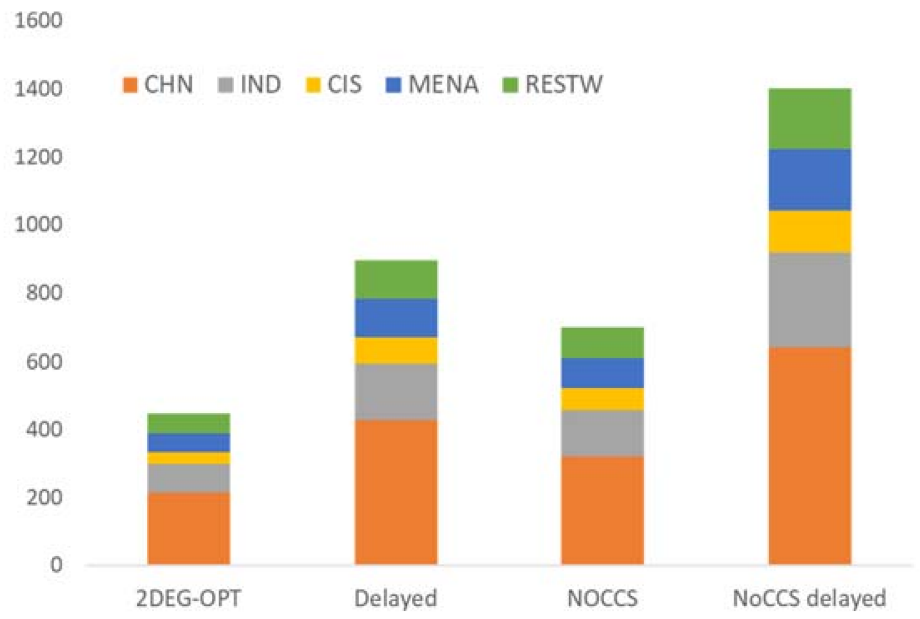

Figure 9. Stranded power generation assets (cumulative over 2020-2050) in developing countries in alternative scenarios (in GW).

Most of stranded assets are projected in China and India (ranging from 210-620 GW to 83-274 GW, respectively, across decarbonisation scenarios), while significant amounts of stranded assets are also found in MENA and RESTW regions. The lowest volumes of stranded assets are projected in the 2DEG-OPT scenario where CCS technologies are massively deployed. These findings confirm that coal may continue to be used in China (at significantly lower levels than today), while a strategic prioritisation of early power plant retirements based on technical, economic and environmental considerations may decrease the risk of stranded assets and enable a near-complete phase-out of coal-fired plants without CCS by 2050 [46]. The risks for stranded assets could be significantly reduced by retrofitting fossil fuel-fired power plants with CCS, with the amount of stranded assets declining by about $33-40 \%$ across developing economies. In contrast, delayed climate policy action leading to the construction of new coal power plants in developing economies by 2030 would significantly increase the risks of stranded assets in order to meet the stringent climate constraints (Figure 10).

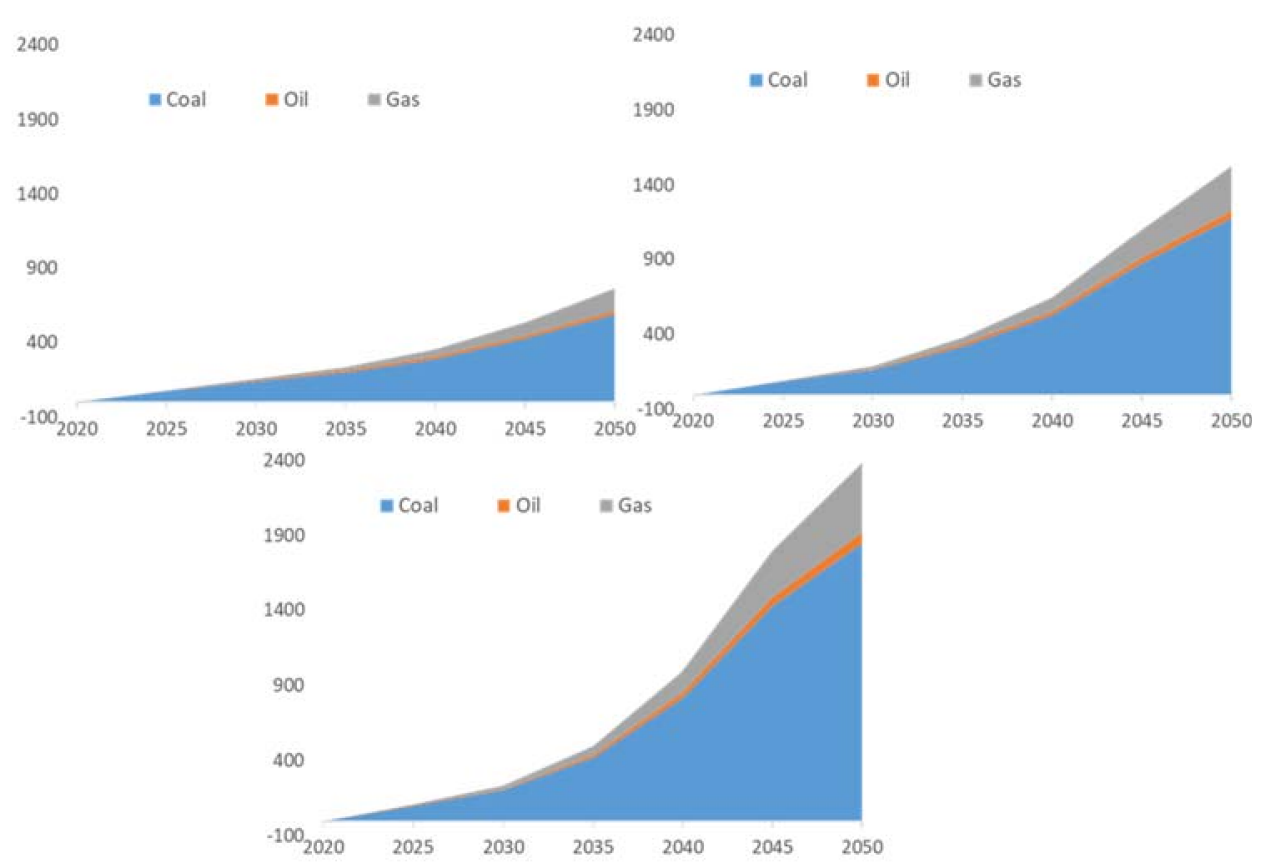

Figure 10. Global Stranded assets in power generation over 2020-2050 by plant type (in billion-bn \$ 2015), upper left: 2DEG-OPT scenario, upper-right: 2DEG-NOCCS, lower: NOCCS-Delayed, Source: PROMETHEUS model results. 


\subsection{Impacts on Mitigation Costs}

The model-based decarbonisation pathways are largely driven by the application of high carbon prices that reflect the ambition of emission reduction effort. The universal carbon price increases to $63 \$ / \mathrm{tnCO}_{2}$ in 2030 and $305 \$ / \mathrm{tnCO}_{2}$ in 2050 in the 2DEGOPT scenario, reflecting the high difficulty to decarbonise hard-to-abate sectors. In the NOCCS scenario, the carbon price is $10 \%$ higher in 2050 , as stronger emission reduction efforts are required to counterbalance the absence of CCS from the spectrum of available mitigation options. These carbon prices are consistent with previous research $[13,14,47]$ and closer to the low-end of reported range, as PROMETHEUS incorporates a high degree of technology granularity.

Energy system decarbonisation is a capital-intensive process characterised by the transition towards clean energy technologies and energy efficiency, which require high upfront capital costs, but result in reduced operation and fuel purchase costs in the longer term. The model-based analysis shows that the 2DEG-OPT scenario would result in higher energy system costs relative to Reference, with the increase across regions ranging between [0.5-1.4] percentage points of GDP (Figure 11). Mitigation costs are generally higher in developing regions, as the imposition of globally-harmonised carbon prices would result in larger relative emission reduction effort in countries with higher carbon intensities, such as China and India, while costs are even higher in the CIS and MENA regions that additionally suffer from reduced fossil fuel export revenues [3]. Cost increases are much lower in developed economies (on average less than $0.7 \%$ of their GDP) as they have low carbon intensities and may benefit from reduced fossil fuel imports. Cost increases are driven by the deployment of costly clean energy technologies and infrastructure to support the transition (e.g., battery recharging, grid investment, storage) and high investment in building retrofits. Lacking some of the emission reduction technologies results in increased abatement costs, as the remaining mitigation options have to be used at levels higher than in 2DEG-OPT with higher marginal costs and closer to their maximum potential. Thus, the absence of CCS would lead to increased deployment of other decarbonisation technologies (e.g., renewable energy, nuclear) at levels higher than their economically optimum level and cause additional cumulative costs of [0.3-1.3] percentage points of GDP across regions compared to 2DEG-OPT over 2025-2050 (Figure 11). Much of the increased costs are directed to storage capacity and grid expansion to support the increased generation from variable RES, combined with costly investment in energy efficiency and nuclear power. The learning potential of low-carbon technologies (triggered by increased learning-by-doing) partly offsets, but cannot cancel out, the increased energy system costs. This also drives increased electricity prices relative to 2DEG-OPT, which make more costly the abatement effort in sectors that rely on electrification, such as transport and buildings.

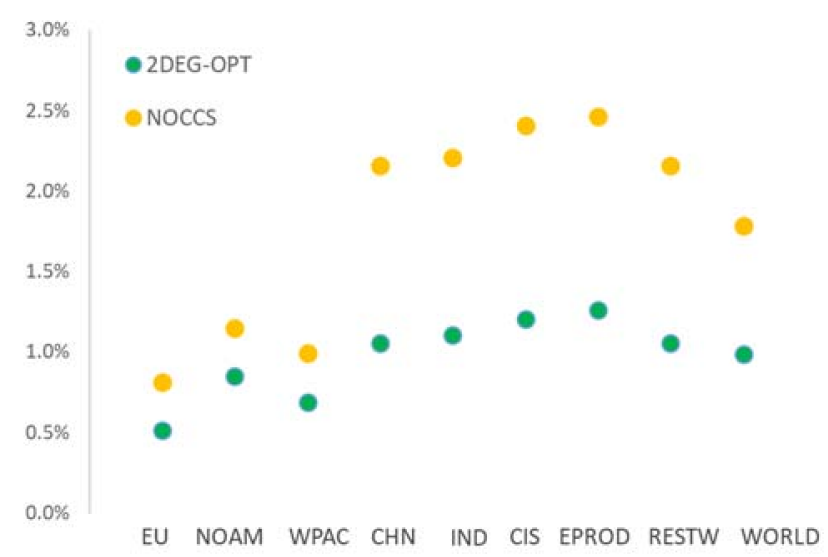

Figure 11. Additional energy system costs by region in decarbonization scenarios relative to reference (as \% of GDP over 2025-2050). 
The comparison across regions shows that the deployment of CCS options can reduce the cumulative mitigation costs in all regions, but the impact is higher in developing regions, where cumulative costs are 1.1-1.3 percentage points of GDP lower than in NOCCS scenario [48]. This implies that the emergence and market uptake of CCS technologies can reduce the global costs to meet the Paris Agreement goals, while substantially alleviating the negative distributional impacts of universal carbon pricing regimes, which tend to disproportionately penalise the developing regions.

\section{Policy Recommendations and Conclusions}

Meeting the ambitious Paris Agreement goals requires an unprecedented transformation of the global energy system with large-scale uptake of renewable energy, acceleration of energy efficiency and fuel switch towards low-emission energy carriers. Carbon capture and storage is also considered an important option to reduce emissions from electricity production and industrial sectors, as it provides a dispatchable option offering flexibility and balancing in future electricity systems with high shares of variable renewable-based generation. However, CCS technologies face high challenges in the last decade related to limited development, technology immaturity, high costs, low public acceptability and limited potential for $\mathrm{CO}_{2}$ storage, thus raising concerns about their potential for massive expansion in the decarbonisation context. Recently, large economies (including the EU, China, and Japan) have pledged carbon neutrality by mid-century, thus necessitating a comprehensive and robust assessment of the impacts, challenges, and potential benefits related to CCS deployment under stringent climate constraints, considering also the COVID-19 impacts and the interplay of CCS with other mitigation options across countries.

The current model-based analysis shows that the development and market uptake of CCS technologies in a decarbonised economy may bring multiple benefits, in the form of reduced global mitigation costs, larger emission reductions, limited risks for carbon lock-in and stranded assets, enabling the cost-effective integration of renewables and alleviating the negative distributional implications of cost-optimal climate policies in developing economies, which are disproportionately affected by universal carbon pricing. Energy system decarbonisation is achieved through extensive expansion of renewable energy, accelerated electrification, and energy efficiency improvements, and fuel switch towards low-emission energy carriers. In the cost-optimal decarbonisation scenario, the deployment of CCS technologies is an important option to reduce emissions from power generation and industries, while the combination of biomass with CCS even leads to net negative emissions to counterbalance remaining emissions from hard-to-abate sectors, such as freight transport. In case that CCS technologies face severe limitations and cannot be massively deployed, other emission reduction options (e.g., renewable energy) have to be used at levels higher than the economically optimum and closer to their maximum potential, thus leading to increased mitigation costs. Model-based findings show that delaying climate efforts until 2030 and limiting CCS deployment have significant adverse effects on energy system costs across regions and stress the system capabilities for decarbonisation by massively increasing the amounts of stranded fossil fuel assets. However, the deployment of CCS technologies poses significant challenges given the uncertainty related to technology development and massive upscale. As CCS prolongs the use of fossil fuels, it increases the risk of enabling the continued construction and investment decisions on associated fossil fuel supply infrastructure and power plants. In addition, the promise of negative emission technologies (such as BECCS) may encourage continued complacency regarding decarbonisation, which may deter or delay climate policy, often referred as "mitigation deterrence" [49]. Well-designed and proactive climate policies should be implemented to reduce these risks and enable investment only in power plants with CCS.

Summing up, the most important conclusions from the study are:

- CCS can be an important technology towards achieving energy system decarbonisation, as it can minimise remaining emissions from power generation and industrial processes. 
- Despite the challenges currently faced by CCS technologies, their market uptake can induce deep emission reduction and alleviate cost increases, especially in developing economies such as China, which can lead the deployment of CCS globally.

- The market uptake of CCS would reduce the risks for carbon lock-in and stranded assets, especially related to coal power plants.

- Climate policy delays and technology limitations for CCS would reduce the capability to achieve carbon neutrality by mid-century and increase energy system costs.

- New coal infrastructure without CCS would likely be inconsistent with the Paris goals.

The current study demonstrates that CCS technologies should be part of a portfolio of emission reduction options to meet the Paris Agreement goals in a cost-optimal manner without negative distributional impacts. As CCS is still in demonstration phase, additional funding should be directed for research and innovation in order to bring down its currently high costs and improve technology performance and integration. The acceleration of CCS deployment would require targeted policies that increase the demand for CCS and further reduce technology costs, through learning-by-doing and economies of scale. These policy instruments may include carbon pricing, public investment, subsidies for low-carbon innovation, tax credits, regulatory support for $\mathrm{CO}_{2}$ grids, and clean energy standards for producing low-carbon electricity with CCS. Overall, CCS should be considered an important part in the policy mix towards cost-optimal decarbonisation, especially in countries facing constraints in the expansion of nuclear power or renewable energy sources.

Author Contributions: Conceptualization, writing — original draft preparation methodology, software, P.F.; All figures included in the manuscript have been developed by the author, using data from the PROMETHEUS model. All authors have read and agreed to the published version of the manuscript.

Funding: The research leading to this study has received funding from the European Union Horizon 2020 research and innovation program under grant agreement No 821124 (NAVIGATE) and No 101003866 (NDC ASPECTS).

Institutional Review Board Statement: Not applicable.

Informed Consent Statement: Not applicable.

Data Availability Statement: Not applicable.

Acknowledgments: The research leading to this study has received funding from the European Union Horizon 2020 research and innovation program under grant agreement No 821124 (NAVIGATE) and No 101003866 (NDC ASPECTS).

Conflicts of Interest: The authors declare no conflict of interest

\section{References}

1. Fragkos, P. Global Energy System Transformations to $1.5^{\circ} \mathrm{C}$ : The Impact of Revised Intergovernmental Panel on Climate Change Carbon Budgets. Energy Technol. 2020, 8, 2000395. [CrossRef]

2. European Commission. Communication from the Commission to the European Parliament, the European Council, the Council, the European Economic and Social Committee and the Committee of the Regions; COM(2019) 640 Final, The European Green Deal; European Commission: Brussels, Belgium, 2019.

3. Fragkos, P.; Fragkiadakis, K.; Paroussos, L. Reducing the decarbonization cost burden for EU energy-intensive industries. Energies 2021, 14, 236. [CrossRef]

4. Paroussos, L.; Mandel, A.; Fragkidakis, K.; Fragkos, P.; Hinkel, J.; Vrontisi, Z. Climate clubs and the macro-economic benefits of international cooperation on climate policy. Nat. Clim. Chang. 2019, 9, 542-546. [CrossRef]

5. McCollum, D.L.; Zhou, W.; Bertram, C.; de Boer, H.; Bosetti, V.; Busch, S.; Després, J.; Drouet, L.; Emmerling, J.; Fay, M.; et al. Energy investment needs for fulfilling the Paris agreement and achieving the sustainable development goals. Nat. Energy 2018. [CrossRef]

6. Fragkos, P. Energy System Transitions and Low-Emission Pathways in Australia, Brazil, Canada, China, EU-28, India, Indonesia, Japan, Republic of Korea, Russia, and United States. Energy 2021, 216, 119385. [CrossRef]

7. Capros, P.; Paroussos, L.; Fragkos, P.; Tsani, S.; Boitier, B.; Wagner, F.; Busch, S.; Resch, G.; Blesl, M.; Bollen, J. European decarbonisation pathways under alternative technological and policy choices: A multi-model analysis. Energy Strategy Rev. 2014, 2, 231-245. [CrossRef] 
8. Marcucci, A.; Panos, E.; Kypreos, S.; Fragkos, P. Probabilistic assessment of realizing the $1.5^{\circ} \mathrm{C}$ climate target. Appl. Energy Appl. Energy 2019, 239, 239-251. [CrossRef]

9. Lund, H.; Mathiesen, B.V. Energy system analysis of $100 \%$ renewable energy systems-The 17 case of Denmark in years 2030 and 2050. Energy 2009, 34, 524-531. [CrossRef]

10. Bogdanov, D.; Farfan, J.; Sadovskaia, K.; Aghahosseini, A.; Child, M.; Gulagi, A.; Solomon, A.; de Souza, L.; Barbosa, N.; Breyer, C. Radical transformation pathway towards sustainable electricity via evolutionary steps. Nat. Commun. 2019, 10, 1077. [CrossRef]

11. De Coninck, H.; Benson, S.M. Carbon dioxide capture and storage: Issues and prospects. Annu. Rev. Environ. Resour. 2014, 39, 243-270. [CrossRef]

12. Lovins, A.B.; Palazzi, T.; Laemel, R.; Goldfiled, E. Relative deployment rates of renewable and nuclear power: A cautionary tale of two metrics. Energy Res. Soc. Sci. 2018, 38, 188-192. [CrossRef]

13. Rogelj, J.D.; Shindel, D.; Jang, K.; Fifita, S.; Forster, P.; Ginzburg, V.; Handa, K.; Khesghi, D.; Kobayashi, S.; Kriegler, E. Mitigation Pathways Compatible with $1.5^{\circ} \mathrm{C}$ in the Context of Sustainable Development in Global Warming of $1.5^{\circ} \mathrm{C}$ : An IPCC Special Report on the Impacts of Global Warming of $1.5^{\circ} \mathrm{C}$ above Pre-Industrial Levels; IPCC: Geneva, Switzerland, 2018.

14. IEA. World Energy Outlook 2019; International Energy Agency: Paris, France, 2019.

15. European Commission. In-Depth Analysis in Support of the Commission Communication COM (2018) 773, A Clean Planet for All: A European Long-Term Strategic Vision for a Prosperous, Modern, Competitive and Climate Neutral Economy; European Commission: Brussels, Belgium, 2018.

16. Global CCS Institute. Global Status of CCS 2019. Available online: https://www.globalccsinstitute.com/wp-content/uploads/20 19/12/GCC_GLOBAL_STATUS_REPORT_2019.pdf (accessed on 10 January 2021).

17. Hoppe, W.; Thonemann, N.; Bringezu, S. Life Cycle Assessment of Carbon Dioxide-Based Production of Methane and Methanol and Derived Polymers. J. Ind. Ecol. 2018, 22, 327-340. [CrossRef]

18. Hepburn, C.; Adlen, E.; Beddington, J.; Carter, E.A.; Fuss, S.; Mac Dowel, N.; Minx, J.C.; Smith, P.; Williams, C.K. The technological and economic prospects for CO2 utilization and removal. Nature 2019, 575, 87-97. [CrossRef]

19. Rosa, L.J.; Reimer, J.A.; Went, M.S.; D’Odorico, P. Hydrological limits to carbon capture and storage. Nat. Sustain. 2020, 3, 658-666. [CrossRef]

20. Muratori, M.; Kheshgi, H.; Mignone, B.; Clarke, L.; McJeon, H.; Edmonds, J. Carbon capture and storage across fuels and sectors in energy system transformation pathways. Int. J. Greenh. Gas Control 2017, 57, 34-41. [CrossRef]

21. Bui, M.; Adjiman, C.; Bardow, A.; Anthony, E.; Boston, A.; Brown, S.; Fennell, P.S.; Fuss, S.; Galindo, A.; Hackett, L. Carbon Capture and Storage (CCS): The way forward. Energy Environ. Sci. 2018, 11, 1062-1176. [CrossRef]

22. Demski, C.; Spence, A.; Pidgeon, N. Effects of exemplar scenarios on public preferences for energy futures using the my2050 scenario-building tool. Nat. Energy 2017, 2, 1-7. [CrossRef]

23. Fowlie, M. “Biden's New Climate Plan” Energy Institute Blog, UC Berkeley. 3 August 2020. Available online: https:// energyathaas.wordpress.com/2020/07/27/how-utility-customers-will-pay-for-the-pandemic/ (accessed on 10 January 2021).

24. McKenzie, B. The European Union's Upcoming Policy and Regulatory Initiatives in the Energy Sector. October 2020. Available online: https:/ /www.bakermckenzie.com/en/insight/publications/2020/10/eu-upcoming-policy-regulatory-initiatives (accessed on 5 February 2021).

25. European Commission. Regulation (EU) 2020/852 of the European Parliament and of the Council of 18 June 2020 on the Establishment of a Framework to Facilitate Sustainable Investment, and Amending Regulation; European Commission: Brussels, Belgium, 2020.

26. Fragkos, P.; Kouvaritakis, N. Model-based analysis of Intended Nationally Determined Contributions and $2{ }^{\circ} \mathrm{C}$ pathways for major economies. Energy 2018, 160, 965-978. [CrossRef]

27. Capros, P.; DeVita, A.; Tasios, N.; Siskos, P.; Kannavou, M.; Petropoulos, A.; Evangelopoulou, S.; Zampara, M.; Papadopoulos, D.; Paroussos, L.; et al. EU Reference Scenario 2016-Energy, Transport and GHG Emissions Trends to 2050; European Commission Directorate General for Energy, Directorate General for Climate Action and Directorate General for Mobility and Transport: Brussels, Belgium, 2016.

28. Fragkos, P.; Tasios, N.; Paroussos, L.; Carpos, P.; Tsani, S. Energy system impacts and policy implications of the European Intended Nationally Determined Contribution and low-carbon pathway to 2050. Energy Policy 2017, 100, 216-226. [CrossRef]

29. IRENA. Stranded Assets and Renewables: How the Energy Transition Affects the Value of Energy Reserves, Buildings and Capital Stock; International Renewable Energy Agency (IRENA): Abu Dhabi, United Arab Emirates, 2017.

30. Pietzcker, R.C.; Ueckerdt, F.; Carrara, S.; Boer, H.; Després, J.; Fujimori, S.; Johnson, N.; Kitousi, A.; Scholz, Y.; Sullivan, P.; et al. System integration of wind and solar power in Integrated Assessment Models: A cross-model evaluation of new approaches. Energy Econ. 2016, 64, 583-599. [CrossRef]

31. Creutzig, F.; Agoston, P.; Goldschmidt, J.; Luderer, G.; Nemet, G.; Pietzcker, R. The underestimated potential of solar energy to mitigate climate change. Nat. Energy 2017, 2, 17140. [CrossRef]

32. Hansen, K.; Breyer, C.; Lund, H. Status and perspectives on 100\% renewable energy systems. Energy 2019, 175, 471-480. [CrossRef]

33. Iyer, G.; Ledna, C.; Clarke, L.; Edmonds, J.; McJeon, H.; Kyle, P.; Williams, J. Measuring progress from nationally determined contributions to mid-century strategies. Nat. Clim. Chang. 2017, 7. [CrossRef]

34. Muratori, M.; Calvin, K.; Wise, M.; Kyle, P.; Edmonds, J. Global economic consequences of deploying bioenergy with carbon capture and storage (BECCS). Environ. Res. Lett. 2016, 11, 095004. [CrossRef] 
35. Vishwanathan, S.S.; Garg, A. Energy system transformation to meet NDC, $2{ }^{\circ} \mathrm{C}$, and well below $2{ }^{\circ} \mathrm{C}$ targets for India. Clim. Chang. 2020, 162, 1877-1891. [CrossRef]

36. Xie, Y.; Liu, X.; Chen, Q.; Zhang, S. An integrated assessment for achieving the $2{ }^{\circ} \mathrm{C}$ target pathway in China by 2030. J. Clean. Prod. 2020, 268, 122238. [CrossRef]

37. Jewell, J.; Vinichenko, V.; McCollum, D.; Bauer, N.; Riahi, K.; Aboumahboub, T.; Fricko, O.; Harmsen, M.; Kober, T.; Krey, V.; et al. Comparison and interactions between the long-term pursuit of energy independence and climate policies. Nat. Energy 2016, 1, 16073. [CrossRef]

38. Fofrich, R.; Tong, D.; Calvin, K.; De Boer, H.; Emmerling, J.; Fricko, O.; Fujimori, S.; Luderer, G.; Rogelj, J.; Davis, S.; et al. Early retirement of power plants in climate mitigation scenarios. Environ. Res. Lett. 2020, 15, 094064. [CrossRef]

39. Malik, A.; Bertram, C.; Despres, J.; Emmerling, J.; Fujimori, S.; Garg, A.; Kriegler, E.; Luderer, G.; Marthur, R.; Roefsema, M.; et al. Reducing stranded assets through early action in the Indian power sector. Environ. Res. Lett. 2020, 15, 9. [CrossRef]

40. Fragkos, P.; Kouvaritakis, N.; Capros, P. Incorporating uncertainty into world energy modelling: The Prometheus model. Environ. Model. Assess. 2015, 20, 549-569. [CrossRef]

41. Rubin, E.S. A review of learning rates for electricity supply technologies. Energy Policy 2015, 86, 198-218. [CrossRef]

42. PRIMES Model Documentation. 2018. Available online: https://e3modelling.com/modelling-tools/primes / (accessed on 4 January 2021).

43. Fricko, O.; Havlik, P.; Rogelj, R.; Klimont, Z.; Gusti, M.; Johnson, N.; Kolp, P.; Strubberger, B.; Valin, H.; Ammann, M.; et al. The marker quantification of the shared socioeconomic pathway 2: A middle-of-the-road scenario for the 21st century. Glob. Environ. Chang. 2017, 42, 251-267. [CrossRef]

44. IRENA. Renewable Power Generation Costs in 2019; International Renewable Energy Agency: Abu Dhabi, United Arab Emirates, 2020.

45. Liu, Z.; Ciais, P.; Deng, Z.; Lei, R.; Davis, S.; Feng, S.; Zheng, B.; Cui, D.; Dou, X.; Zhu, B.; et al. Near-real-time monitoring of global $\mathrm{CO}_{2}$ emissions reveals the effects of the COVID-19 pandemic. Nat. Commun. 2020, 11, 5172. [CrossRef]

46. IEA. Sustainable Recovery; International Energy Agency: Abu Dhabi, United Arab Emirates, 2020.

47. Karkatsoulis, P.; Capros, P.; Fragkos, P.; Paroussos, L.; Tsani, S. First-mover advantages of the European Union's climate change mitigation strategy. Int. J. Energy Res. 2016, 40, 814-830. [CrossRef]

48. He, G.; Lin, J.; Zhang, Y.; Zhang, W.; Larangeira, G.; Zhang, C.; Peng, W.; Liu, M.; Yang, F. Enabling a Rapid and Just Transition away from Coal in China. One Earth 2020, 3, 187-194. [CrossRef]

49. Mc Laren, D. Quantifying the potential scale of mitigation deterrence from greenhouse gas removal techniques. Clim. Chang. 2020, 162, 2411-2428. [CrossRef] 